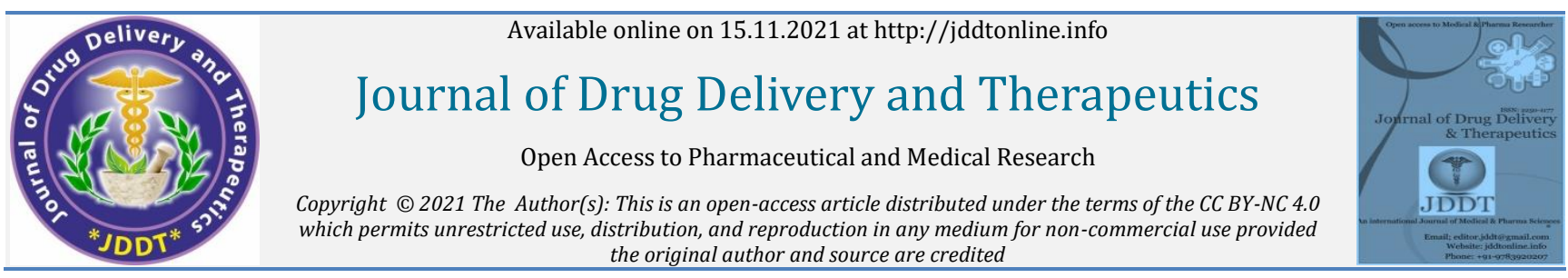
the original author and source are credited

Research Article

Open Access Full Text Article

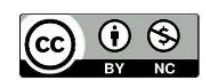

\title{
Effect of Recrystallization Technique on Oral Bioavailability of Valsartan
}

\author{
TP. Rao, Buchi N. Nalluri* \\ Department of Pharmaceutics and Biotechnology, KVSR Siddhartha college of pharmaceutical sciences, Vijayawada, AP, India
}

Article Info:

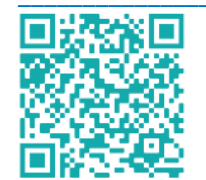

Article History:

Received 11 September 2021 Reviewed 24 October 2021

Accepted 02 November 2021

Published 15 November 2021

\section{Cite this article as:}

Rao TP, Nalluri BN, Effect of Recrystallization Technique on Oral Bioavailability of Valsartan, Journal of Drug Delivery and Therapeutics. 2021 11(6):88-93

DOI: http://dx.doi.org/10.22270/jddt.v11i6.5064

*Address for Correspondence:

Buchi N. Nalluri, Department of Pharmaceutics and Biotechnology, KVSR Siddhartha college of pharmaceutical sciences, Vijayawada, AP, India ${ }^{¥}$ Both the authors contributed equally

\author{
Abstract
}

Valsartan (VAL) is a widely prescribed anti-hypertensive agent with angiotensin II type I receptor antagonistic activity. VAL belongs to BCS class II having a low and variable oral bioavailability (10-35\%) and its absorption is dissolution rate limited. Recrystallization of VAL from different organic solvents improved VAL aqueous solubility and thereby in vitro dissolution properties. In this investigation in vivo oral bioavailability (BA) of VAL and its recrystallized products with methanol and ethanol (VMET and VETH respectively) solvents was evaluated in male Wistar rats. Also, a rapid, economical and reliable RP-HPLC-PDA method was developed for the estimation of VAL in rat plasma samples and validated according to ICH guidelines. Chromatographic separation was achieved on an Agilent eclipse $\mathrm{C}_{18}$ column $(150 \times 4.6 \mathrm{~mm}, 5 \mu)$ with a mobile phase composition of $10 \mathrm{mM}$ ammonium acetate: acetonitrile $(75: 25 \% \mathrm{v} / \mathrm{v})$ at a flow rate of $1.2 \mathrm{~mL} / \mathrm{min}$. The retention time of VAL was found to be $2.9 \mathrm{~min}$ and showed good linearity $\left(\mathrm{R}^{2}>0.996\right)$ in the selected concentration range of $0.5-25 \mu \mathrm{g} / \mathrm{mL}$. A $2.9,2.8$ folds increase in $\mathrm{C}_{\max }$ and a relative bioavailability of $320,305 \%$ was observed with VMET and VETH respectively, when compared to that of untreated VAL. Thus it can be inferred that recrystallization is easy and economical technique for enhancing the pharmaceutical properties like solubility, dissolution properties and oral BA of poorly water soluble drugs like VAL.

Keywords: Bioanalytical method, Bioavailability, Male Wistar rats, Valsartan, Recrystallization

\section{INTRODUCTION}

Bioavailability (BA) is the rate and extent at which a drug moiety enters systemic circulation, thereby gaining access to the respective site of action. In case of oral administration, the oral BA depends on numerous factors like the physicochemical properties of drug, various aspects of dosage form, the physiological aspects of GI tract, etc. Oral BA of solid dosage forms (tablets, capsules) depends mainly on solubility of drug particles in GI fluids and permeability of dissolved drug molecules across GI membranes ${ }^{1}$.

Valsartan (VAL) is widely prescribed; potent oral antihypertensive agents with angiotensin II type I (AT 1 ) receptor antagonistic activity. It is a BCS class II molecule and was reported to have a low and variable absolute oral bioavailability of about $10-35 \%$ (averaged at $25 \%$ ) and its absorption is dissolution rate limited 2,3 . Several techniques were reported to increase dissolution properties of VAL and thus enhancing its oral BA including solid dispersions, cyclodextrin inclusion complexes, formulation of selfmicroemulsifying drug delivery system (SMEDDS), reduction in particle size (micro- and nanosuspensions), etc ${ }^{4-7}$.

Crystal morphology has a great effect on the physicochemical properties of the drug and many drug molecules exist in more than one crystal forms (polymorphism). Modifying and controlling the crystalline nature of a drug via recrystallization can improve several pharmaceutical properties of drugs like stability, solubility, rate of dissolution, etc. which in turn may affect the absorption and BA of the drug8. An earlier study by the authors on the evaluation of the effect of recrystallization on various properties of VAL inferred in significant improvement in aqueous solubility and in vitro dissolution properties of recrystallized products when compared to untreated VAL $^{9}$. Since, orally administered drugs must dissolve in the aqueous medium of GIT prior to absorption, the improvement of the solubility and the rate of dissolution of poorly soluble drugs can be seen as first steps towards the improvement in oral bioavailability. In vitro dissolution tests seem to be sensitive and reliable for prediction of BA, yet in vitro testing cannot always predict the in vivo performance.

Hence, in the present investigation, the oral BA of pure VAL and its recrystallized products (VMET and VETH) were evaluated using male Wistar rats. Such enhancement in oral BA was represented in terms of improvement in various pharmacokinetic parameters like $\mathrm{C}_{\max }$, AUC, etc. Several analytical methods were reported in literature for estimation of VAL alone and in combination with other drugs in bulk, pharmaceutical dosage forms and human plasma samples ${ }^{10}$ 13. It was also aimed to develop and validate a rapid, economical and sensitive RP-HPLC-PDA bioanalytical method for the estimation of VAL in rat plasma samples. 


\section{MATERIALS AND METHODS}

\section{Materials}

VAL was provided by Aurobindo Pharma Ltd (Hyderabad, India). Acetonitrile, Ammonium acetate, Ethanol, Methanol, were purchased from Loba Chemie Pvt, Ltd., (Mumbai, India).Male Wistar ratswere obtained from Mahaveer enterprises (Hyderabad, India).All the chemicals and reagents used inHPLC studies are of HPLC grade.

\section{Methods}

\section{Analytical Method}

The assay of VAL in plasma samples was performed on a Shimadzu Prominence HPLC system equipped with DGU$20 \mathrm{~A} 3$ degasser, LC-20AD binary pumps, SIL-20ACHT auto sampler with $200 \mu \mathrm{L}$ loop volume, programmable variable wavelength PDA detector SPD-M20A VP. Data acquisition and processing was carried out using LC-Solution software. The proposed bio analytical method was validated for linearity, system suitability, stability, intra-day and inter-day precision, accuracy, limit of detection and limit of quantification parameters according to ICH guidelines ${ }^{14}$.

\section{Preparation of VAL recrystallization products}

$2 \mathrm{~g}$ of VAL were added to $5 \mathrm{~mL}$ of a specific pure organic solvent (ethanol and methanol) in a $15 \mathrm{~mL}$ beaker and heated slowly to $45^{\circ} \mathrm{C}$ to afford a supersaturated solution. The resulting mixture was then cooled down to room temperature. The resulting recrystallized drug was then collected, dried at $40^{\circ} \mathrm{C}$ for $15 \mathrm{~min}$, and passed through a \#80 sieve to obtain a product of uniform particle size. The powdered drug was packed in glass bottles and stored in a desiccator until use ${ }^{9}$.

\section{Oral BA study in rats}

Male Wistar rats, weighing 200-220g at the start of each experiment, were obtained from Mahaveer enterprises, Hyderabad, India. Rats were acclimated to the colony for 7 days before the start of experiments. Standard rat chow (Harlan) and filtered water $(0.22 \mu \mathrm{m})$ were available continuously and were maintained on a light/dark cycle in which the lights were on from 0600 to 2000 hours. All animal studies were carried out in accordance with institutional guidelines approved by the IAEC. The test compounds, VAL and recrystallized products (VMET and VETH) were suspended in $0.5 \%$ Natrosol 250 HX (hydroxy ethyl cellulose) at room temperature 30 minutes before administration. The VAL and its recrystallized products were administered at a dose of $10 \mathrm{mg} / \mathrm{kg}$. Administration was performed by oral gavage and the animals were offered water $1 \mathrm{~h}$ p.a. and standard laboratory diet $2 \mathrm{~h}$ p.a. ad libitum.

Blood samples $(\sim 0.2 \mathrm{~mL})$ were withdrawn (into $2 \mathrm{~mL}$ collection tubes containing a drop of heparinized saline) at different time intervals from tail vein and after the sampling, the volume was replaced with same volume of heparinized saline. The animals were offered water $1 \mathrm{~h}$ p.a. and standard laboratory diet $2 \mathrm{~h}$ p.a. ad libitum. Plasma from these blood samples was obtained by centrifuging at 5,000 rpm for 10 min and samples were stored at $-20^{\circ} \mathrm{C}$ until analysis by HPLC.

\section{Pharmacokinetic Analysis}

Pharmacokinetic analysis was performed using noncompartmental methods. The maximum plasma concentration $\left(\mathrm{C}_{\max }\right)$ and time to reach $\mathrm{C}_{\max }\left(\mathrm{T}_{\max }\right)$ were determined by direct observation of the plasma concentration-time profiles. The elimination rate constant $\left(\mathrm{K}_{\mathrm{el}}\right)$ was obtained from the terminal slope using regression analysis, and the half-life $\left(\mathrm{t}_{1 / 2}\right)$ of the drug was calculated by the relationship of $0.693 / \mathrm{Kel}_{\mathrm{el}}$ The area under the plasma concentration-time curve to the final measurable sample $\left(\mathrm{AUC}_{0-24} \mathrm{~h}\right)$ was calculated by the trapezoidal rule and extrapolated to infinity $\left(\mathrm{AUC}_{0-\infty}\right)$, with the final observed plasma concentration divided by $\mathrm{K}_{\mathrm{el}}$. The relative bioavailability (F) of the products was calculated as percentage AUC of recrystallized VAL to that of pure VAL.

\section{Statistical Analysis of the data}

All the data was given as mean \pm SD. Statistical analysis of the data wascarried out with a one-way ANOVA analysis (using Fisher's Least-Significant-Difference post hoc test) using SYSTAT 13 software (Systat Software Inc., CA, USA). Statistical significance was checked at a threshold of $p<0.05$.

\section{RESULTS}

\section{Bio analytical method}

Chromatographic separation of VAL in plasma samples was achieved on an Agilent eclipse $\mathrm{C}_{18}$ column $(150 \times 4.6 \mathrm{~mm}, 5 \mu)$ at ambient temperature. The mobile phase consisted of Acetonitrile and $10 \mathrm{mM}$ ammonium acetate $(25: 75 \% \mathrm{v} / \mathrm{v})$, pumped at a flow rate of $1.2 \mathrm{~mL} / \mathrm{min}$. The separation was carried out using $10 \mu \mathrm{L}$ injection volume with acetonitrile: $10 \mathrm{mM}$ ammonium acetate $(25: 75 \mathrm{v} / \mathrm{v})$ as diluent. The total runtime was set at $6 \mathrm{~min}$ while the retention time of VAL was found to be $2.9 \mathrm{~min}$. Quantification of VAL was carried out by PDA detector set at $254 \mathrm{~nm}$. The optimized method using above LC conditions was validated according to ICH guidelines ${ }^{14}$.

\section{Extraction of VAL from Plasma:}

VAL was extracted from plasma by adding $500 \mu \mathrm{L}$ of acetonitrile and centrifuged at $10,000 \mathrm{rpm}$ for $10 \mathrm{~min}$. The supernant was collected and evaporated under nitrogen flow and finally the residue was reconstituted with $200 \mu \mathrm{L}$ of diluent (acetonitrile: ammonium acetate $-25: 75 \% \mathrm{v} / \mathrm{v}$ ). The extraction efficiency of the method was found to be more than $95 \%$

\section{Method validation:}

\section{Specificity and selectivity}

Selectivity of the method was demonstrated by comparing the chromatograms of the blank sample of the plasma (spiked with acetonitrile in place of drug) and a VAL standard $(25 \mu \mathrm{g} / \mathrm{mL})$. The chromatograms of blank plasma and standard samples were shown in (Fig. 1). From the chromatograms it was clearly evident that no interference peak was present at the retention time of VAL i.e. $2.9 \mathrm{~min}$. The same was confirmed by peak purity index values $(\geq 0.999)$. 

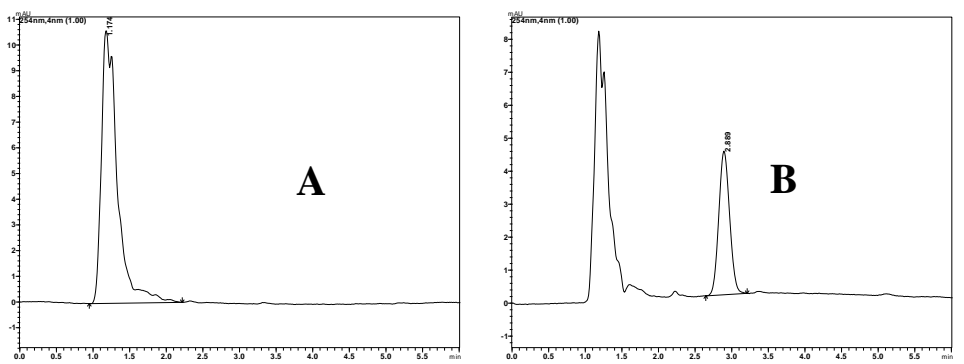

Figure 1: Chromatograms of the blank plasma sample (A); VAL plasma standard-25 $\mu \mathrm{g} / \mathrm{mL}$ (B)

\section{Linearity}

The linearity of this method was evaluated by linear regression analysis, which was calculated by least Squares method in the concentration range of $0.5-25 \mu \mathrm{g} / \mathrm{mL}$ both in plasma and diluent. The coefficient of regression for the calibration curves was found to be 0.996 and can be concluded that there was an excellent correlation between peak area and analyte concentration. The data was given in Table I and the overlay of chromatograms was shown in Fig.2.

Table I: Validation data of VAL RP-HPLC-PDA method

Validation data of VAL

\section{Linearity $(n=3)$}

Range

Regression equation

Regression coefficient $\left(\mathrm{R}^{2}\right)$

Correlation coefficient (R)

LOD

LOQ
$0.5-25 \mu \mathrm{g} / \mathrm{mL}$

$\mathrm{y}=1860.1 \mathrm{x}-93.467$

$\mathrm{R}=0.996$

$\mathrm{R}^{2}=0.996$

$0.045 \mu \mathrm{g} / \mathrm{mL}$

$0.1 \mu \mathrm{g} / \mathrm{mL}$

\section{$\operatorname{Accuracy}(\mathrm{n}=3)$}

(\% level of addition)

\begin{tabular}{cc}
\hline 80 & $99.35(1.36)$ \\
100 & $99.58(1.67)$ \\
120 & $100.13(1.89)$ \\
\hline Precision & Average Peak Area (\% RSD) \\
Inter-day (n=9) & $27851(0.529)$ \\
\hline
\end{tabular}

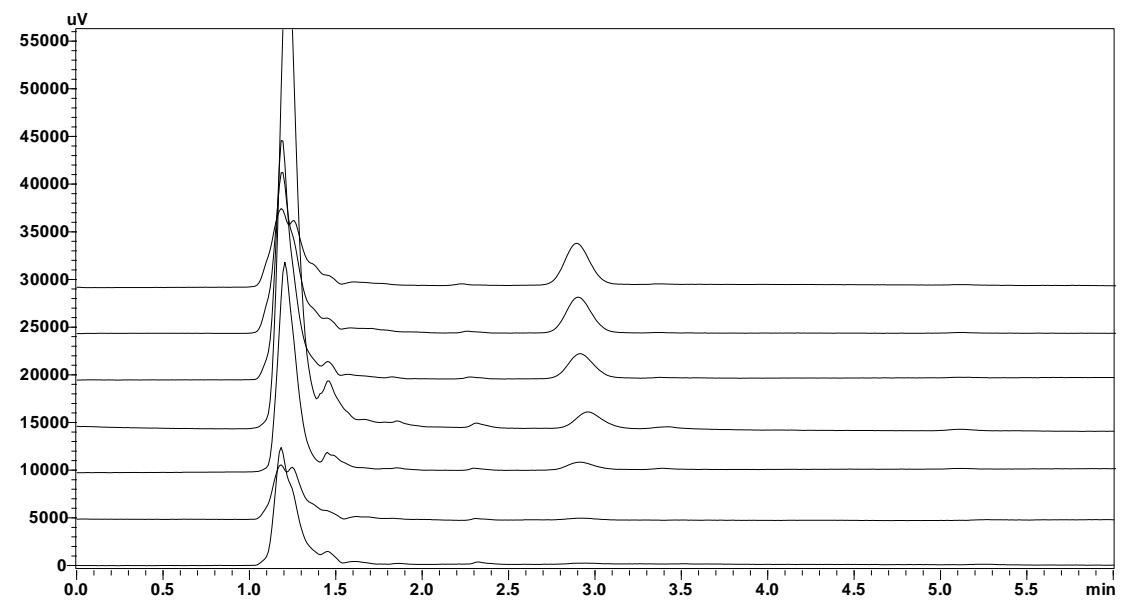

Figure 2: Ovelay chromatograms of VAL at different concentrations in plasma $(0.5-25 \mu \mathrm{g} / \mathrm{mL})$ 


\section{Precision and Accuracy}

Precision and accuracy were studied by covering low, medium and high concentrations $(5,15,10$ and $25 \mu \mathrm{g} / \mathrm{mL})$ of VAL within the range of linearity. The \%RSD for VAL was found to be less than 2 for the four concentrations with respect to both Intra-day and inter-day (3 consecutive days).

Accuracy of the method was determined by recovery studies. Statistical evaluation revealed that \%RSD of the drug at different concentration levels for six injections was less than 3. Precision and accuracy data was shown in Table I.

\section{Limit of detection (LOD) and limit of quantification (LOQ)}

The LOD and LOQ values were determined by the formulae $\mathrm{LOD}=3.3 \sigma / \mathrm{m}$ and LOQ $=10 \sigma / \mathrm{m}$ (Where, $\sigma$ is the standard deviation of the responses and $m$ is mean of the slopes of the calibration curves), given in Table I.

\section{System suitability}

System suitability was established by injecting six replicates of standard sample at various volumes $(10-50 \mu \mathrm{L})$ and the parameters (mean [RSD]) like plate number $(\mathrm{N}=5306$ [0.01]), tailing factor $(\mathrm{T}=1.29[0.12])$ and retention time $\left(\mathrm{R}_{\mathrm{t}}\right.$ $=2.9[0.05]$ ) and peak symmetry of samples were studied. All the specifications were found to be within limits.

\section{Stability of solutions}

The short-term stability of the plasma samples was determined by analysing the samples kept at room temperature at different time intervals up to $24 \mathrm{hrs}$. Also, the freeze-thaw stability of plasma samples was assessed over 3 consecutive cycles of freezing (24h) and thawing (24h), followed by extraction procedure and analysed. The variation in assay values at different time intervals were found to be less than $3 \%$ of the initial zero time, indicating that the samples were stable over the entire duration of experiment.

\section{Bioavailability (BA) Studies in Rats}

A parallel study design was adopted since it was practically impossible to give each rat the five different treatments in crossover with long enough wash out periods to prevent any sequence effect (Table II). Mean plasma concentration-time profiles for VAL and its recrystallized products (VMET and VETH) were presented in Fig. 3. Pharmacokinetic parameters such as $\mathrm{C}_{\max }, \mathrm{T}_{\max }, \mathrm{AUC}_{0-24 \mathrm{~h}}$ and $\mathrm{AUC}_{0-\infty}$ for all the treatments were computed and given in Table III and the statistical analysis of the parameters using one way ANOVA analysis (using Fisher's LSD post hoc Test) was given in Table IV.

Table II: The dose groups and numbers assigned to rats in a parallel study design

\begin{tabular}{cccc}
\hline Group & Formulation & Dose $[\mathbf{m g} / \mathbf{k g}]$ & Animal No. \\
\hline G 1 & VAL & 10 & $101-104$ \\
G 2 & VMET & 10 & $201-204$ \\
G 3 & VETH & 10 & $301-304$ \\
\hline
\end{tabular}

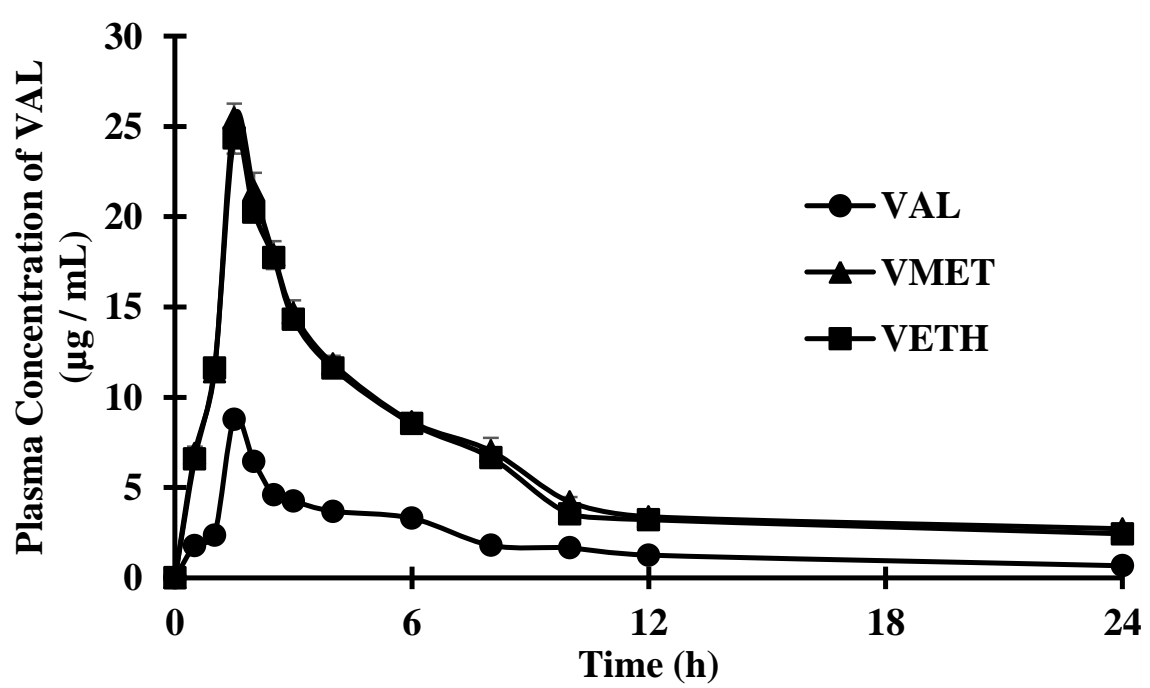

Figure 3: Mean comparative plasma concentration - time profiles of VAL and recrystallized products ( $\mathrm{n}=4$ )

\section{DISCUSSION}

The developed bioanalytical method showed good correlation between the peak area and concentration of the drug under developed LC conditions and also the VAL recoveries were found to be $>97.4 \%$. A linearity range of $0.5-25 \mu \mathrm{g} / \mathrm{mL}$ for VAL was established for quantification. The differences of less than $3.0 \%$ in RSD for both intra- and inter-day data reflect the high degree of precision of the method. The developed bioanalytical method was successfully applied for quantifying VAL in rat plasma samples.
VAL is a BCS class II drug, with dissolution of drug in GI fluids as the rate limiting step for absorption, and several strategies reported in literature for the enhancement of dissolution and oral BA of VAL. Dixit AR et al., 2010, discussed the enhancement of VAL oral BA by formulation of self-microemulsifying drug delivery system (SMEDDS). A 1.36 fold enhancement in oral BA was reported for SMEEDS when compared to market formulations of VAL ${ }^{4}$. Yana YD et al., 2012, reported a 43 fold increase in solubility and 2.2 fold increase in relative oral BA of VAL in rat model, with a shorter $\mathrm{T}_{\max }$ when compared to pure VAL using VAL-loaded 
solid dispersions composed of hydroxypropyl methylcellulose (HPMC) and sodium lauryl sulphate (SLS). Moreover, no change in the crystallinity of VAL was reported due to formation of solid dispersions ${ }^{5}$.

De Matos et al., 2010, discussed the efficiency of cyclodextrin inclusion complexation on enhancement of dissolution and oral BA of VAL. Several methods were employed for preparation of complexes and freeze drying method was found to be more efficient, resulting in up to 16 times increase in dissolution rate, with a significant increase in oral BA of VAL ${ }^{6}$. Qiuping M et al., 2012, studied the effect of particle size and crystalline state on dissolution and oral BA of VAL. Micro- $(\sim 22 \mu \mathrm{m})$ and nano- $(30-80 \mathrm{~nm})$ suspensions of VAL were prepared by high speed dispersing and antisolvent precipitation method and converted into powders through spray drying. The VAL nanosuspenstion was reported to be in amorphous state while the microsuspension retained its crystalline nature. The study demonstrated a 2.5 fold improvement in oral BA in case of nanosuspension (amorphous) when compared to crude VAL (crystalline), while such improvement was reported to be only marginal with microcrystals ${ }^{7}$.

Recrystallization is a simple and very economical physical modification technique that affects the physical and physicochemical properties of drugs such as melting point, solubility, true density, tabletability, etc. which in turn alters the pharmaceutical properties of drugs like rate of dissolution, rate and extent of absorption, etc. In our earlier paper, we observed that recrystallization of VAL using different solvents like methanol, ethanol, isopropyl alcohol, acetonitrile, acetone, etc. resulted in different polymorphs of VAL with altered physical characteristics, as confirmed by SEM, DSC and Powder X-RD Studies. It was found that the aqueous solubility of VAL increased by about 2 orders of magnitude after recrystallization with different solvents and that the various in vitro dissolution parameters like drug percent dissolved at $10 \mathrm{~min}\left(\mathrm{DP}_{10}\right)$ and $120 \mathrm{~min}\left(\mathrm{DP}_{120}\right)$, dissolution efficiency at $20 \mathrm{~min} \quad\left(\mathrm{DE}_{20}\right)$ improved significantly for some recrystallized products when compared to pure $\mathrm{VAL}^{9}$.

Since, it was found that both solubility and in vitro dissolution properties of VAL improved significantly by recrystallization, there is good probability that the recrystallized products also have improved absorption (BA). Consistent with that idea, in the present investigation, in vivo oral BA studies were carried out in male Wistar rats as animal models. The various pharmacokinetic parameters viz. $\mathrm{C}_{\text {max }}, \mathrm{T}_{\text {max }}, \mathrm{AUC}_{0-} 24, \mathrm{AUC}_{0-} \infty$ etc. of pure $\mathrm{VAL}$ and its recrystallized products (VMET, VETH) were computed and compared (Table III, IV).

Table III: Pharmacokinetic parameters of VAL and its recrystallized products $(n=4)$

\begin{tabular}{ccccc}
\hline Treatment & $\begin{array}{c}\mathbf{C}_{\text {max }} \\
(\mu \mathrm{g} / \mathbf{m L})\end{array}$ & $\begin{array}{c}\mathbf{T}_{\max } \\
(\mathbf{h r s})\end{array}$ & $\begin{array}{c}\text { AUC-24 } \\
(\mu \mathrm{g} . \mathbf{h r} / \mathbf{m L})\end{array}$ & $\begin{array}{c}\text { AUC }_{\mathbf{0}-\infty} \\
(\mu \mathrm{g} . \mathbf{h r} / \mathbf{m L})\end{array}$ \\
\hline VAL & $8.79 \pm 0.31$ & $1.5 \pm 0.00$ & $46.53 \pm 0.71$ & $58.01 \pm 2.59$ \\
VMET & $25.46 \pm 0.81$ & $1.5 \pm 0.00$ & $149.33 \pm 2.20$ & $214.40 \pm 2.36$ \\
VETH & $24.35 \pm 0.85$ & $1.5 \pm 0.00$ & $142.27 \pm 3.39$ & $187.24 \pm 0.26$ \\
\hline
\end{tabular}

Table IV: Statistical summary of pharmacokinetic parameters for VAL (Fisher's LSD post hoc test)

\begin{tabular}{cccc}
\hline Groups compared & $\begin{array}{c}\mathbf{C}_{\max } \\
(\mu \mathrm{g} / \mathbf{m l})\end{array}$ & $\begin{array}{c}\text { AUCo-24 } \\
(\boldsymbol{\mu g} \cdot \mathbf{h r} / \mathbf{m l})\end{array}$ & $\begin{array}{c}\text { AUCo- } \\
(\boldsymbol{\mu g} \cdot \mathbf{h r} / \mathbf{m l})\end{array}$ \\
\hline VAL vs. VMET & $\mathrm{S}(3.00 \mathrm{E}-08)$ & $\mathrm{S}(2.98 \mathrm{E}-09)$ & $\mathrm{S}(9.51 \mathrm{E}-11)$ \\
VAL vs. VETH & $\mathrm{S}(3.99 \mathrm{E}-08)$ & $\mathrm{S}(4.56 \mathrm{E}-09)$ & $\mathrm{S}(2.98 \mathrm{E}-10)$ \\
VMET vs. VETH & $\mathrm{NS}(0.143)$ & $\mathrm{S}(0.011)$ & $\mathrm{S}(3.28 \mathrm{E}-06)$ \\
\hline
\end{tabular}

*S = significant, NS = not significant; Values in parentheses were $p$ values.

When compared to the pure VAL, the $\mathrm{C}_{\max }$ values for recrystallized products (VMET and VETH) increased by 2.9 and 2.8 folds respectively. A similar trend was also observed with $\mathrm{AUC}_{0-\infty}$ values. Recrystallization of VAL using the selected solvents significantly improved the pharmacokinetic parameters considered $(p<0.05)$ except for the $T_{\max }$ values which remained constant for pure and recrystallized VAL. Among the two recrystallized products (VMET and VETH), significant variation was not observed with $\mathrm{C}_{\max }$ values $(p>0.05)$. However, the $\mathrm{AUC}_{0-} 24, \mathrm{AUC}_{0-\infty}$ values differed significantly $(p<0.05)$. Moreover, relative BA of recrystallized products with respect to pure VAL was found to be $320 \%$ and 305\% for VMET and VETH respectively.

Overall, it can be inferred that recrystallization under different conditions has significantly improved the oral BAof VAL, and it may be beneficial to develop solid oral dosage forms of VAL using its recrystallized products. Moreover, the enhancement in oral BA of VAL by recrystallization was found to be superior and relative easy and economical when compared to different strategies previously reported in the literature.

\section{CONCLUSION}

Our investigation proves the potential of recrystallization, a physical modification technique, in enhancing the oral BA of a poorly soluble drug, VAL. It was observed that the methanol recrystallized product of VAL (VMET) showed a relative BA of $320 \%$ compared to pure VAL. It may therefore be concluded that recrystallization is a very simple, economical technique that can be easily applied on commercial scale, capable of full automation of process, for improving various properties of poorly water soluble drugs like solubility, dissolution parameters, oral BA and overall ADME behaviours in vivo after administration. 


\section{ACKNOWLEDGEMENTS}

The authors are thankful to Aurobindo Pharma Ltd (Hyderabad, India) for providing a gift sample of VAL. The authors are also thankful to the Siddhartha Academy of General and Technical Education, Vijayawada, for providing facilities to carry out the research work.

\section{CONFLICT OF INTEREST}

Nil

\section{REFERENCES}

1. Sarwar B, Suryakanta S, Rizwan Md, Irfanuddin Md, Shobha D.M. Bioavailability Enhancement Strategies: Basics, Formulation Approaches and Regulatory Considerations. Current Drug Delivery, 2011; 8(6):691-702 https://doi.org/10.2174/156720111797635504

2. Flesch G, Lloyd P, Müller P.H. Absolute bioavailability and pharmacokinetics of valsartan, an angiotensin II receptor antagonist. Eur J Clin Pharmacol., 1997; 52:115-120. https://doi.org/10.1007/s002280050259

3. Nadeem S, Asif H, Lakshita C, Shamsher M.A, Mitra M, Parminder S.B. Pharmacological and Pharmaceutical Profile of Valsartan: A Review. Journal of Applied Pharmaceutical Science, 2011; 01 (04):12-19.

4. Dixit A.R, Rajput SJ, Patel S.G. Preparation and Bioavailability Assessment of SMEDDS Containing Valsartan. AAPS PharmSciTech, 2010;11(1):314-321. https://doi.org/10.1208/s12249-010-9385-0

5. Yana Y.D, Sunga J.H, Kima K.K, Kimb D.W, Kima J.O, Leec B.J, Yonga C.S, Choi H.G. Novel valsartan-loaded solid dispersion with enhanced bioavailability and no crystalline changes. International Journal of Pharmaceutics, 2012; 422(1-2):202210. https://doi.org/10.1016/j.ijpharm.2011.10.053

6. Qiuping M, Hongrui S, Erxi C, Xin Z, Tongying J, Changshan S, Siling W. Uniform nano-sized valsartan for dissolution and bioavailability enhancement: Influence of particle size and crystalline state. International Journal of Pharmaceutics, 2012
$441(1-2): 75-81$

https://doi.org/10.1016/j.ijpharm.2012.12.025

7. De Matos Jensen C.E, Dos Santos R.A.S, Denadai A.M.L, Santos C.F.F, Braga A.N.G; Sinisterra R.D. Pharmaceutical Composition of Valsartan: $\beta$-Cyclodextrin: Physico-chemical characterization and anti-hypertensive evaluation. Molecules, 2010; 15:40674084. https://doi.org/10.3390/molecules15064067

8. Amit C, Upendra N, Neha G, Sharma V.K, Khosa R.L. Enhancement of solubilization and bioavailability of poorly soluble drugs by physical and chemical modifications: A recent review. Journal of Advanced Pharmacy Education \& Research, 2012; 2(1):32-67.

9. Nalluri B.N, Ramya K.M, Rao T.P, Peter A.C. Effect of Recrystallization on the Pharmaceutical Properties of Valsartan for Improved Therapeutic Efficacy. Journal of Applied Pharmaceutical Science, 2012; 2(10):126-132. https://doi.org/10.7324/JAPS.2012.21025

10. Samya M.E, Osama H.A, Mahmoud A.O, Sayed M.D. Development and Validation of HPLC Method for Simultaneous Determination of Amlodipine, Valsartan, Hydrochlorothiazide in Dosage Form and Spiked Human Plasma. American Journal of Analytical Chemistry, 2012; 3:422-430.

https://doi.org/10.4236/ajac.2012.36055

11. Bhatia M.S, Kokil S.U. Determination and validation of valsartan and its degradation products by isocratic HPLC. J. Chem. Metrl, 2009; (3)1:1-12.

12. Macek J, Klima J, Ptacek P. Rapid determination of valsartan in human plasma by protein precipitation and high-performance liquid chromatography. Journal of Chromatography B, 2006; 832(1):169-172. https://doi.org/10.1016/j.jchromb.2005.12.035

13. Nozomu K, Hiroto K, Hisanori H, Miyuki N, Makoto T, Ryosei K, Yusuke N, Naoki M. Development and validation of a method for quantitative determination of valsartan in human plasma by liquid chromatography-tandem mass spectrometry. Journal of Pharmaceutical and Biomedical Analysis, 2007; 43(5):17691774. https://doi.org/10.1016/j.jpba.2006.12.030

14. International Conference on Harmonization of Technical Requirements for Registration of Pharmaceuticals for Human use. Validation of Text and Methodology Q2 (R1), 2005. 